\title{
Agent Affecting Respiratory System
}

National Cancer Institute

\section{Source}

National Cancer Institute. Agent Affecting Respiratory System. NCI Thesaurus. Code C78273.

An agent that exerts a physiologic effect on any anatomic entity that is part of the respiratory tract and airways. 